\title{
Increase in depression and anxiety disorder diagnoses during the COVID-19 pandemic in children and adolescents followed in pediatric practices in Germany
}

\author{
Karel Kostev $^{1} \mathbb{D} \cdot$ Kerstin Weber $^{2} \cdot$ Steffi Riedel-Heller ${ }^{3} \cdot$ Christian von Vultée $^{1} \cdot$ Jens Bohlken $^{3}$
}

Received: 25 May 2021 / Accepted: 23 November 2021

(c) The Author(s), under exclusive licence to Springer-Verlag GmbH Germany 2021

\begin{abstract}
The coronavirus pandemic and related restrictions impacted the daily lives of children and youth, partly due to the closure of schools and the absence of outdoor activities. The aim of this study was to investigate, quantify, and critically discuss the effect of the pandemic and related restrictions on consultations pertaining to depression and anxiety disorders in children and adolescents. This retrospective cross-sectional study was based on medical record data from the Disease Analyzer database (IQVIA) and included all children and adolescents aged 2-17 years with at least one visit to one of 168 German pediatric practices between April 2019 and December $2019(n=454,741)$ or between April 2020 and December $2020(n=417,979)$. The number of children and adolescents with depression and anxiety disorder diagnoses per practice and the prevalence of these diagnoses were compared for April 2020-December 2020 versus April 2019-December 2019. The number of children and adolescents with depression and anxiety diagnoses per practice increased in April 2020-December 2020 compared to the same period in 2019 (anxiety: $+9 \%$, depression: $+12 \%$ ). The increase was much greater in girls than in boys (anxiety: $+13 \%$ vs. $+5 \%$; depression $+19 \%$ vs. $+1 \%)$. The prevalence of anxiety disorder increased from 0.31 to $0.59 \%(p<0.001)$, and that of depression from 0.23 to $0.47 \%(p<0.001)$. The biggest increases were observed for girls (anxiety from 0.35 to $0.72 \%$ $(+106 \%, p<0.001)$, depression from 0.28 to $0.72 \%(+132 \%, p<0.001)$. This study shows an increase in the number of pediatric diagnoses of depression and anxiety disorders in the pandemic year 2020 compared to the previous year.
\end{abstract}

Keywords COVID-19 pandemic $\cdot$ Children $\cdot$ Adolescents $\cdot$ Depression $\cdot$ Anxiety disorder

\section{Introduction}

Since its first description in China in December 2019, COVID-19 has spread around the world and subsequently induced a severe pandemic (1). To prevent healthcare systems from being overwhelmed and to slow the spread of the disease, governments worldwide implemented a range of non-pharmaceutical measures at varying levels of intensity

Karel Kostev

karel.kostev@iqvia.com

Epidemiology, IQVIA, Unterschweinstiege 2-14, 60549 Frankfurt am Main, Germany

2 Retired Pediatrician, Currently Senior Physician at COVID-19 Vaccination Center, Berlin, Germany

3 Institute for Social Medicine, Occupational Medicine, and Public Health (ISAP) of the Medical Faculty at the University of Leipzig, Leipzig, Germany
(2). In Germany, these measures included, among others, the closure of schools and public playgrounds as well as a recommendation for businesses to allow and facilitate remote working (3).

The coronavirus pandemic and lockdowns also impacted the daily lives of children and youth, partly due to the closure of schools and the absence of outdoor activities. A number of Asian and European studies have shown that a significant proportion of children and adolescents are suffering from mental health problems as a result of the coronavirus pandemic or the related measures (4-17).

Ravens-Sieberer investigated the mental health and quality of life of children and adolescents during the pandemic in Germany. A total of 1586 parents with 7- to 17-year-old children and adolescents as well as 1040 children and adolescents were surveyed. Authors found that overall, $71 \%$ of children and adolescents felt burdened by the pandemic, reporting stressful homeschooling, less contact with their friends, and more arguments in the family. In addition, the 
prevalence of mental health problems increased from $18 \%$ before the COVID-19 pandemic to $30 \%$ during the crisis (13).

In their study of 1,146 children aged 12-17 in Switzerland, Mohler-Kuo et al. reported that during the COVID-19 pandemic, the prevalence rates of anxiety symptoms were $13.6 \%$ for girls and $12.5 \%$ for boys, and the prevalence rates of depression symptoms were $9.7 \%$ among girls and $4.6 \%$ among boys (14). Nearchou et al. provided a systematic review of the evidence concerning the impact of the COVID19 pandemic on the mental health of children and adolescents, based on 12 studies. They reported the prevalence of anxiety symptoms as being between 18.9 and $37.4 \%$, and depression symptoms as between 22.6 and $43.7 \%$ (15). Panda et al. analyzed 15 studies including 22,996 children and adolescents, where $34.5 \%$ were found to be suffering from anxiety and $41.7 \%$ from depression (16).

Although the studies published investigating the effect of the pandemic on the mental health of children and adolescents are of great interest, most of these are based on relatively small numbers of individuals and therefore might not be representative. Thus far, no database- or registry-based studies have been published in Germany that empirically examine the influence of the coronavirus lockdowns on the prevalence of depression and anxiety disorders in children or adolescents, documented in pediatric practices. Pediatricians assume primary care physician functions in Germany. Parents of children and adolescents usually first contact pediatricians, who then refer their young patients to psychiatrists. In addition, database studies allow for the use of longitudinal data pertaining to large, often nationwide sample sizes in a relatively short time.

The aim of this study was to investigate, quantify, and critically discuss the effect of the pandemic and related restrictions on consultations pertaining to psychiatric problems in children and adolescents. Our hypothesis is that the number of children and adolescents with depression and anxiety disorders may increase in the pandemic time.

\section{Methods}

\section{Database}

This retrospective cross-sectional study was based on medical record data from the Disease Analyzer database (IQVIA), which compiles drug prescriptions, diagnoses, and general medical and demographic data obtained directly in anonymous format from computer systems used in the practices of general practitioners (GP) and specialists (14). Diagnoses, prescriptions, and the quality of the reported data are monitored by IQVIA based on an array of criteria. In Germany, the sampling methods used to select physicians' practices have been shown to be appropriate for obtaining a population-representative database of primary and specialized care practices (18). This database has already been used for a number of studies on COVID-19 $(19,20)$.

\section{Participants}

This study included all children and adolescents aged 2-17 years with at least one visit to one of 168 German pediatric practices between April 2019 and December 2019 or between April 2020 and December 2020. The database used has a coverage of approximately $3.5 \%$ for pediatric practices. These practices provide complete information on consultations and diagnoses of children and adolescents followed in them. German law allows the use of anonymous electronic medical records for research purposes under certain conditions. According to this legislation, it is not necessary to obtain informed consent from patients or approval from a medical ethics committee for this type of observational study that contains no directly identifiable data. Because patients were only queried as aggregates and no protected health information was available for queries, no institutional review board approval was required for the use of this database or the completion of this study.

\section{Procedure and outcomes}

The first outcome was the difference in the number of children and adolescents with at least one visit to these practices between April 2020 and December 2020 versus between April 2019 and December 2019. Comparisons were stratified by sex and age group (2-5, 6-9, 10-12, and 13-17 years). We used the classification we had often seen in other studies as we thought it was correct: small children ( $0-5$ years), school children (6-12 years) and adolescents (13-17 years). However, we also further stratified 6-12-year-olds into two groups $(6-9,10-12)$ as this makes a difference between children attending primary school (first 4 years) and those attending secondary school in Germany-primary schools were not closed for as long as secondary schools.

The second outcome was the number of children and adolescents with depression (ICD-10: F32, F33) and anxiety disorder diagnoses (ICD-10: F41) per practice April 2020-December 2020 versus April 2019-December 2019. This analysis was also performed for new depression and anxiety disorder diagnoses, defined as diagnoses not previously documented in the database, to show patients who were initially diagnosed with depression or anxiety disorder during the coronavirus pandemic.

The third outcome of the study was the change in the prevalence of depression and anxiety disorder diagnoses in April 2020-December 2020 versus April 2019-December 2019. The prevalence rate was defined as the number 
of children and adolescents diagnosed with depression or anxiety disorder in the selected period divided by the total number of children and adolescents with at least one visit within the same period.

\section{Statistical analyses}

Chi-squared tests were used to compare the prevalence between two time periods. The number of patient visits per practice as well as the number of children and adolescents with depression and anxiety disorder diagnoses per practice was compared for April 2020-December 2020 versus April 2019-December 2019 using a Wilcoxon signed-rank test. A $p$-value of $<0.05$ was considered statistically significant in all analyses. The analyses were carried out using SAS 9.4 (SAS Institute, Cary USA).

\section{Results}

\section{Study population}

This study included 454,741 pediatric patients in the period April 2019-December 2019, and 417,979 patients in the period April 2020-December 2020. The baseline characteristics are shown in Table 1 . There were partly significant differences in age between 2019 and 2020, but these were very small in terms of absolute numbers.

\section{Changes in consultations per practice}

Table 2 shows the differences by sex and age in the number of patients with at least one visit per practice between April 2019-December 2019 or April 2020-December 2020. The number of patients per practice was lower in April-December 2020 than in April 2020-December 2019 (2488 vs. $2,707,-8 \%, p=0.037$ ). These differences were

Table 1 Age and sex characteristics of patients with at least one visit to one of 168 German pediatric practices between April 2019 and December 2019 and April 2020 and December 2020

\begin{tabular}{llll}
\hline Patient group & $\begin{array}{l}\text { April 2019- } \\
\text { December } \\
2019\end{array}$ & $\begin{array}{l}\text { April 2020- } \\
\text { December } \\
2020\end{array}$ & $P$-value \\
& 454,741 & 417,979 & \\
\hline $\mathrm{N}$ & $6.6(4.9)$ & $6.7(5.0)$ & $<0.001$ \\
Average age (mean, SD) & 49.3 & 48.4 & $<0.001$ \\
Age 2-5 years (\%) & 21.8 & 21.8 & 0.889 \\
Age 6-9 years (\%) & 13.4 & 13.7 & 0.002 \\
Age 10-12 years (\%) & 15.3 & 16.1 & $<0.001$ \\
Age 13-17 years (\%) & 47.7 & 47.6 & 0.096 \\
Girls (\%) & 52.3 & 52.4 & \\
Boys (\%) & & &
\end{tabular}

Table 2 Differences by sex and age in the number of patients with at least one visit to one of 168 German pediatric practices between April 2019 and December 2019, or April 2020 and December 2020

\begin{tabular}{lllll}
\hline Patient group & $\begin{array}{l}\text { April 2019- } \\
\text { December } \\
2019 \\
\text { (Mean, SD) }\end{array}$ & $\begin{array}{l}\text { April 2020- } \\
\text { December } \\
\text { (Mean, SD) } \\
\text { (Merference }\end{array}$ & $\begin{array}{l}\text { P-value } \\
\text { in \% }\end{array}$ & \\
\hline Total & $2,707(1,133)$ & $2488(1,098)$ & -8 & 0.037 \\
Age 2-5 years & $1,338(595)$ & $1205(581)$ & -10 & 0.011 \\
Age 6-9 years & $591(244)$ & $543(236)$ & -8 & 0.041 \\
Age & $363(158)$ & $339(150)$ & -7 & 0.141 \\
$\quad$ 10-12 years & & & & \\
Age & $415(212)$ & $401(204)$ & -3 & 0.455 \\
$\quad$ 13-17 years & & & & \\
Girls & $1,292(539)$ & $1183(518)$ & -8 & 0.029 \\
Boys & $1,415(597)$ & $1305(582)$ & -8 & 0.048 \\
\hline
\end{tabular}

observed for both girls and boys as well as different age groups. The most prominent differences $(-10 \%)$ occurred in the age group 2-5 years.

\section{Changes in depression and anxiety patients per practice}

The number of children and adolescents with depression and anxiety diagnoses per practice increased in April 2020-December 2020 compared to the same period in 2019 (anxiety: $+9 \%$, depression: $+12 \%$, Table 3 ). The increase was much greater in girls than in boys (anxiety: $+13 \%$ vs. $+5 \%$; depression $+19 \%$ vs. $+1 \%)$. The increase of both anxiety $(+16 \%)$ and depression $(+29 \%)$ was strongest in the age group 10-12 years. Although none of the differences observed met the criteria for statistical significance due to the low number of practices included, they still provide important insights about the changes caused by the pandemic in Germany. This trend was also observed for new diagnoses $(+13 \%$ for anxiety, $+18 \%$ for depression). At $+29 \%$, the increase in depression in girls was significant $(p=0.010)$ (Table 3$)$.

\section{Changes in the rate of depression and anxiety}

The rate of anxiety disorder increased from 0.31 to $0.59 \%$ $(p<0.001$, Fig. 1a), and that of depression from 0.23 to $0.47 \%$ ( $p<0.001$, Fig. 1b). The biggest increases were observed for girls (anxiety from 0.35 to $0.72 \%(+106 \%$, $p<0.001$, Fig. 1a), depression from 0.28 to $0.65 \%$ $(+132 \%, p<0.001$, Fig. 1b). 
Table 3 Differences by sex and age in the number of patients with depression and anxiety disorder diagnoses who visited one of 168 German pediatric practices between April 2019 and December 2019 and April 2020 and December 2020

\begin{tabular}{|c|c|c|c|c|c|c|c|c|}
\hline \multirow[t]{2}{*}{ Patient group } & \multicolumn{4}{|l|}{ All diagnoses } & \multicolumn{4}{|c|}{ New diagnoses } \\
\hline & $\begin{array}{l}\text { April 2019- } \\
\text { December } \\
2019 \\
\text { (Mean, SD) }\end{array}$ & $\begin{array}{l}\text { April 2020- } \\
\text { December } \\
2020 \\
\text { (Mean, SD) }\end{array}$ & Difference in $\%$ & $P$-value & $\begin{array}{l}\text { April 2019- } \\
\text { December } \\
2019 \\
\text { (Mean, SD) }\end{array}$ & $\begin{array}{l}\text { April 2020- } \\
\text { December } \\
2020 \\
\text { (Mean, SD) }\end{array}$ & Difference in $\%$ & $P$-value \\
\hline \multicolumn{9}{|l|}{ Anxiety disorder } \\
\hline Total & $10.1(14.2)$ & $11.1(16.7)$ & +9 & 0.478 & $7.6(9.8)$ & $8.6(12.0)$ & +13 & 0.309 \\
\hline Age $2-5$ years & $2.3(8.7)$ & $2.3(9.9)$ & 0 & 0.535 & $1.9(6.4)$ & $1.9(7.6)$ & +2 & 0.623 \\
\hline Age $6-9$ years & $2.3(2.9)$ & $2.6(4.0)$ & +13 & 0.525 & $1.9(2.4)$ & $2.3(3.4)$ & +17 & 0.564 \\
\hline Age $10-12$ years & $2.3(2.6)$ & $2.6(3.1)$ & +16 & 0.205 & $1.9(2.2)$ & $2.3(2.5)$ & +20 & 0.105 \\
\hline Age $13-17$ years & $3.3(2.9)$ & $3.6(3.3)$ & +9 & 0.568 & $2.5(2.3)$ & $2.9(2.7)$ & +12 & 0.492 \\
\hline Girls & $5.5(7.3)$ & $6.2(9.1)$ & +13 & 0.596 & $4.1(4.9)$ & $4.8(6.8)$ & +16 & 0.470 \\
\hline Boys & $4.7(7.2)$ & $4.9(7.9)$ & +5 & 0,730 & $3.5(5.3)$ & $3.8(5.7)$ & +9 & 0.416 \\
\hline \multicolumn{9}{|l|}{ Depression } \\
\hline Total & $8.5(9.3)$ & $9.5(9.9)$ & +12 & 0.315 & $5.9(6.7)$ & $7.0(7.2)$ & +18 & 0.086 \\
\hline Age $2-5$ years & - & - & & & - & - & & \\
\hline Age $6-9$ years & $0.6(1.0)$ & $0.6(1.0)$ & 0 & 0.994 & $0.5(0.9)$ & $0.5(0.9)$ & +2 & 0.966 \\
\hline Age $10-12$ years & $1.3(1.8)$ & $1.6(2.5)$ & +29 & 0.221 & $1.1(1.6)$ & $1.4(2.3)$ & +32 & 0.110 \\
\hline Age $13-17$ years & $6.5(7.4)$ & $7.2(7.6)$ & +10 & 0.365 & $4.4(5.4)$ & $5.2(5.3)$ & +16 & 0.086 \\
\hline Girls & $5.2(5.9)$ & $6.2(6.6)$ & +19 & 0.128 & $3.5(4.2)$ & $4.5(4.6)$ & +29 & 0.010 \\
\hline Boys & $3.3(3.9)$ & $3.3(4.0)$ & +1 & 0.892 & $2.4(3.0)$ & $2.5(3.2)$ & +3 & 0.910 \\
\hline
\end{tabular}

\section{Discussion}

This study conducted in 168 pediatric practices in Germany showed that the total number of children and adolescents with anxiety disorder and depression, the number of children and adolescents newly diagnosed with anxiety disorder and depression, and the prevalence of anxiety disorder and depression among children and adolescents increased in April-December 2020 compared to April-December 2019.

In addition, this increase was the strongest in girls and in children aged 10-12 years. To the best of our knowledge, this is one of the largest studies carried out on this topic in Germany to date, and is also the first study to use pediatric diagnoses.

In our study, the prevalence rates for anxiety and depression were much lower than in other publications (14-16), as only confirmed medical diagnoses by pediatricians were used, and individual symptoms of mental disorders do not necessarily result in diagnoses even when these symptoms are reported to or observed by pediatricians. We observed a significant increase in the rates of both anxiety and depression during the COVID-19 pandemic, but the proportion of children with these mental health diagnoses was relatively low. The strong increase in the rate of anxiety and depression diagnoses in our study may be due to the fact that the number of patients with consultations decreased while the number of patients diagnosed with anxiety and depression increased.
It is known that prevalence rate estimates based primarily on self-reporting of symptoms as used by online survey results differ from the prevalence documented in medical practices (21). In view of this, it is important to consider the specific conditions of pediatric and adolescent medicine practices in Germany. The pandemic had far-reaching consequences for pediatricians concerning the provision of services (22): the frequency of contact and also the density of services decreased, in particular the number of acute illnesses of the respiratory system decreased, fewer preventive examinations were carried out, and sick leave for parents caring for sick children was no longer necessary because many parents were working from home. Finally, many services were provided by telephone or video contact (22). Revet et al. estimated the impact of COVID-19 on child and adolescent psychiatry services in Europe and they reported that the perceived impact on the mental health and psychopathology of children and adolescents dramatically increased in 2020 and 2021 (11).

One particularly striking result of the present study is the development of mental disorders in school children aged 10-12 years as well as adolescents (13-17 years). These age groups is in an important transitional phase (23-25), which is usually characterized by the transition to secondary school, the onset of puberty, and an incipient detachment from the parental home and increased contact with the peer group. The strong increase in the anxiety and depression prevalence in the age group 13-17 may result from the lack 
Fig. 1 Differences by sex and age in the prevalence of depression and anxiety disorder diagnoses in 168 German pediatric practices between April 2019 and December 2019 and April 2020 and December 2020

\section{a Anxiety}

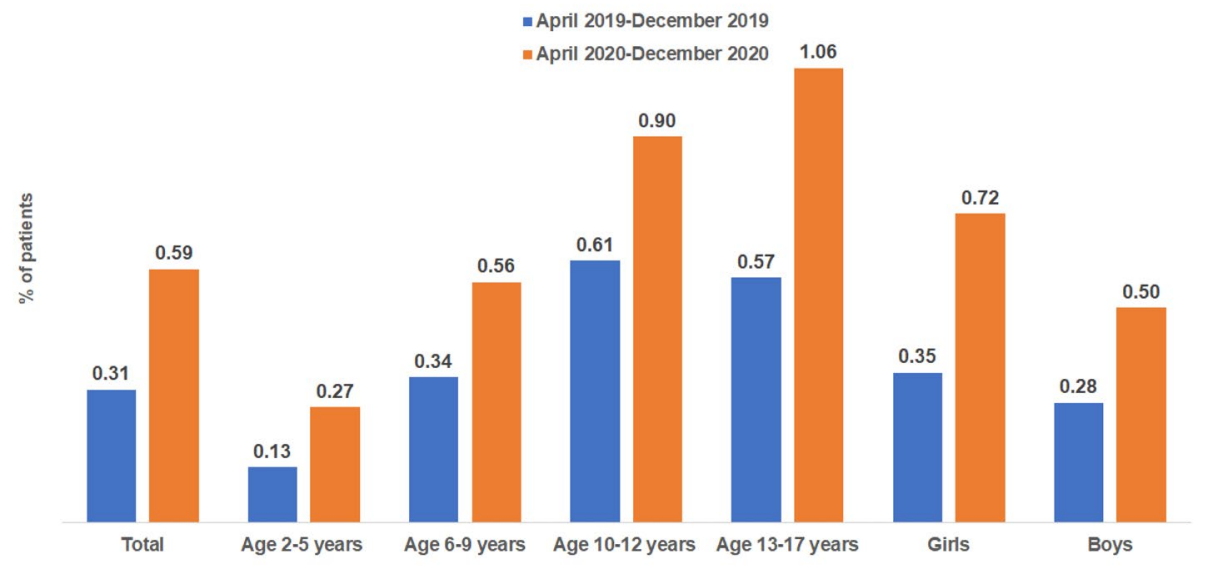

\section{b Depression}

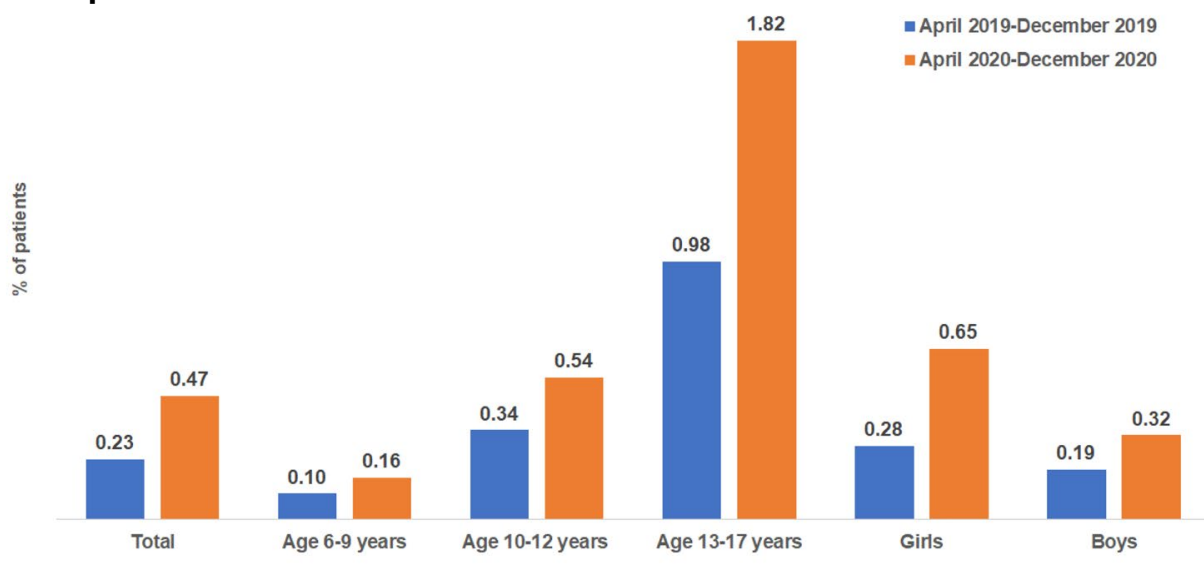

of access to health services usually provided through schools (26).

Although the data used for this study do not allow direct indications to be derived for measures aimed at reducing or treating anxiety or depression in children and adolescents, there are already a number of reviews in which possible interventions are presented (27). It has been pointed out that children and adolescents are a particularly vulnerable group due to the development of mental disorders such as anxiety and depression, and that certain subgroups, including female patients, are at a higher risk.

There is much evidence that quarantine measures can be associated with negative psychological consequences (28). For example, lockdowns caused drastic modifications to children's routines. Schools, which are responsible for providing structure and routine to children and adolescents' daily lives, were closed. Physical activity, which is associated with lower levels of depression and anxiety was curtailed. Social relations and friendships, which are important for maintaining mental health, were also severely restricted (29).

Among children and adolescents, this particularly affects children in crowded living conditions where there is a chronic family conflict situation (e.g., divorce, separation, parental mental illness) (30).

We do not currently know the extent to which repetitive lockdowns continue to produce volatile situations with unpredictable consequences for children's mental health. Furthermore, without appropriate therapy, these mental disorders may have a negative impact on further child development, not only during the pandemic but also after it has ended. It is important to develop more targeted interventions to mitigate the negative impact of the pandemic on child and adolescent mental health. With this in mind, child and adolescent psychiatrists and psychotherapists as well as social centers and even government officials are calling for a recovery plan for children, adolescents, and their families (31). 
In contrast to existing studies on mental health problems in children and adolescents during the COVID-19 pandemic which used surveys, our study features a large cohort of children that are representative for the sociodemographic situation in Germany and uses retrospective data from pediatric practices. A further advantage of this study is that database studies can show if there are inconsistencies between mental health burden detected in community samples and service utilization. We acknowledge that this work is subject to several limitations. First, the number of practices included in the analysis is relatively small. Second, misclassification or underestimation of individual diagnoses may have occurred due to the use of the ICD-10 coding system. Third, this study is based on data from pediatric practices, which assume a primary care physician functions in Germany, but psychiatrists are ultimately responsible for the treatment of depression and anxiety in children and adolescents. No data from psychiatrists were used in this study.

Fourth, the German Disease Analyzer database does not contain details of how diagnoses were made. Fifth, this database does not provide information on lifestyle or socioeconomic status, and the data available do not allow disease severity to be analyzed. Sixth, we only analyzed depression and anxiety disorder and did not focus on any other psychiatric disorders as these are rarely documented by pediatricians. Seventh, we cannot validate there was an increase in depression and anxiety diagnoses because there were more children with depression and anxiety or because more children with depression and anxiety sought help from professionals.

Finally, this study is of a descriptive nature and no complex statistic methods such as time-series analyses were used.

Nevertheless, the database presents a relevant overview of the diagnosis of depression and anxiety disorder among children and adolescents during the COVID-19 pandemic and shows an interesting shift in the number of pediatric diagnoses in the pandemic year 2020 compared to the previous year. Further studies on the impact of the COVID-19 pandemic and especially lockdowns and quarantine measures are needed in the near future, both during and after the end of the pandemic.

Funding This research did not receive any specific grants from funding agencies in the public, commercial, or not-for-profit sectors.

\section{Declarations}

Conflict of interests The authors declare that they have no competing financial interests.

\section{References}

1. Franchini AF, Auxilia F, Galimberti PM, Piga MA, Castaldi S, Porro A (2020) COVID 19 and Spanish flu pandemics: all it changes, nothing changes. Acta Biomed 91(2):245-250. https:// doi.org/10.23750/abm.v91i2.9625

2. Flaxman S, Mishra S, Gandy A, Unwin HJT, Mellan TA, Coupland H, Whittaker C, Zhu H, Berah T, Eaton JW, Monod M; Imperial College COVID-19 Response Team, Ghani AC, Donnelly CA, Riley S, Vollmer MAC, Ferguson NM, Okell LC, Bhatt S. Estimating the effects of non-pharmaceutical interventions on COVID-19 in Europe. Nature. 2020 Aug;584(7820):257-261. doi: https://doi.org/10.1038/s41586-020-2405-7

3. Huber M, Langen H (2020) Timing matters: the impact of response measures on COVID-19-related hospitalization and death rates in Germany and Switzerland. Swiss J Econ Stat 156(1):10. https://doi.org/10.1186/s41937-020-00054-w

4. Chen F, Zheng D, Liu J, Gong Y, Guan Z, Lou D (2020) Depression and anxiety among adolescents during COVID-19: a crosssectional study. Brain Behav Immun 88:36-38. https://doi.org/10. 1016/j.bbi.2020.05.061

5. Saurabh K, Ranjan S (2020) Compliance and psychological impact of quarantine in children and adolescents due to COVID19 pandemic. Indian J Pediatr 87(7):532-536. https://doi.org/10. 1007/s12098-020-03347-3

6. Jiao WY, Wang LN, Liu J, Fang SF, Jiao FY, Pettoello-Mantovani M, Somekh E (2020) Behavioral and emotional disorders in children during the COVID-19 epidemic. J Pediatr 221:264-266.e1. https://doi.org/10.1016/j.jpeds.2020.03.013

7. Saddik B, Hussein A, Albanna A, Elbarazi I, Al-Shujairi A, Temsah MH, Saheb Sharif-Askari F, Stip E, Hamid Q, Halwani R (2021) The psychological impact of the COVID-19 pandemic on adults and children in the United Arab Emirates: a nationwide cross-sectional study. BMC Psychiatry 21(1):224. https://doi.org/ 10.1186/s12888-021-03213-2

8. Boldt K, Coenen M, Movsisyan A, Voss S, Rehfuess E, Kunzler AM, Lieb K, Jung-Sievers C (2021) Interventions to ameliorate the psychosocial effects of the COVID-19 pandemic on children-a systematic review. Int J Environ Res Public Health 18(5):2361. https://doi.org/10.3390/ijerph18052361

9. Bignardi G, Dalmaijer ES, Anwyl-Irvine AL, Smith TA, Siugzdaite R, Uh S, Astle DE. Longitudinal increases in childhood depression symptoms during the COVID-19 lockdown. Arch Dis Child. 2020 Dec 9:archdischild-2020-320372. doi: https://doi.org/ 10.1136/archdischild-2020-320372

10. Berger E, Jamshidi N, Reupert A, Jobson L, Miko A (2021) Review: the mental health implications for children and adolescents impacted by infectious outbreaks - a systematic review. Child Adolesc Ment Health 26(2):157-166. https://doi.org/10. 1111/camh. 12453

11. Revet A, Hebebrand J, Anagnostopoulos D, et al. Perceived impact of the COVID-19 pandemic on child and adolescent psychiatric services after 1 year (February/March 2021): ESCAP CovCAP survey [published online ahead of print, 2021 Jul 29]. Eur Child Adolesc Psychiatry. 2021;1-8. doi:https://doi.org/10.1007/ s00787-021-01851-1

12. Schmidt SJ, Barblan LP, Lory I, Landolt MA (2021) Age-related effects of the COVID-19 pandemic on mental health of children and adolescents. Eur J Psychotraumatol 12(1):1901407

13. Ravens-Sieberer U, Kaman A, Otto C, Adedeji A, Napp AK, Becker M, Blanck-Stellmacher U, Löffler C, Schlack R, Hölling H, Devine J, Erhart M, Hurrelmann K. Mental health and psychological burden of children and adolescents during the first wave of the COVID-19 pandemic-results of the COPSY study]. Bundesgesundheitsblatt Gesundheitsforschung Gesundheitsschutz. 2021 Mar 1:1-10. German. doi: https://doi.org/10.1007/ s00103-021-03291-3

14. Mohler-Kuo M, Dzemaili S, Foster S, Werlen L, Walitza S (2021) Stress and Mental Health among children/adolescents, their parents, and young adults during the first COVID-19 lockdown in 
Switzerland. Int J Environ Res Public Health 18(9):4668. https:// doi.org/10.3390/ijerph18094668

15. Nearchou F, Flinn C, Niland R, Subramaniam SS, Hennessy E (2020) Exploring the impact of COVID-19 on mental health outcomes in children and adolescents: a systematic review. Int J Environ Res Public Health 17(22):8479. https://doi.org/10.3390/ ijerph17228479

16. Panda PK, Gupta J, Chowdhury SR, Kumar R, Meena AK, Madaan P, Sharawat IK, Gulati S. Psychological and Behavioral Impact of Lockdown and Quarantine Measures for COVID-19 Pandemic on Children, Adolescents and Caregivers: A Systematic Review and Meta-Analysis. J Trop Pediatr. 2021 Jan 29;67(1):fmaa122. doi: https://doi.org/10.1093/tropej/fmaa122

17. Panchal U, Salazar de Pablo G, Franco M, Moreno C, Parellada M, Arango C, Fusar-Poli P. The impact of COVID-19 lockdown on child and adolescent mental health: systematic review. Eur Child Adolesc Psychiatry. 2021 Aug 18:1-27. doi: https://doi.org/10. 1007/s00787-021-01856-w

18. Rathmann W, Bongaerts B, Carius HJ, Kruppert S, Kostev K (2018) Basic characteristics and representativeness of the German Disease Analyzer database. Int J Clin Pharmacol Ther 56(10):459-466

19. Michalowsky B, Hoffmann W, Bohlken J, Kostev K (2021) Effect of the COVID-19 lockdown on disease recognition and utilisation of healthcare services in the older population in Germany: a cross-sectional study. Age Ageing 50(2):317-325. https://doi.org/ 10.1093/ageing/afaa260

20. Jacob L, Loosen SH, Kalder M, Luedde T, Roderburg C, Kostev $\mathrm{K}$ (2021) Impact of the COVID-19 pandemic on cancer diagnoses in general and specialized practices in Germany. Cancers (Basel) 13(3):408. https://doi.org/10.3390/cancers 13030408

21. Pierce M, McManus S, Jessop C, John A, Hotopf M, Ford T, Hatch S, Wessely S, Abel KM (2020) Says who? The significance of sampling in mental health surveys during COVID-19. Lancet Psychiatry 7(7):567-568. https://doi.org/10.1016/S2215-0366(20) 30237-6

22. Mangiapane S, Zhu L, Kretschmann J, Czihal T, von Stillfried D. Veränderung der vertragsärztlichen Leistungsinanspruchnahme während der COVID-Krise. https://www.zi.de/fileadmin/images/ content/Publikationen/Trendreport_4_Leistungsinanspruchn ahme_COVID_2021-04-19.pdf accessed on 17.05.2021

23. Bathelt J, Vignoles A, Astle DE (2021) Just a phase? Mapping the transition of behavioural problems from childhood to adolescence.
Soc Psychiatry Psychiatr Epidemiol 56(5):821-836. https://doi. org/10.1007/s00127-020-02014-4

24. Leebens PK, Williamson ED (2017) Developmental psychopathology: risk and resilience in the transition to young adulthood. Child Adolesc Psychiatr Clin N Am 26(2):143-156. https://doi. org/10.1016/j.chc.2016.12.001

25. Holz NE, Nees F, Meyer-Lindenberg A, Tost H, Hölling H, Keil T, Brandeis D, Romanos M, Banaschewski T. Kohortenstudien in der Kinder- und Jugendpsychiatrie [Cohort studies in child and adolescent psychiatry]. Nervenarzt. 2021 Mar;92(3):208-218. German. doi: https://doi.org/10.1007/s00115-020-01018-4

26. Jones EAK, Mitra AK, Bhuiyan AR. Impact of COVID-19 on Mental Health in Adolescents: A Systematic Review. Int J Environ Res Public Health. 2021;18(5):2470. Published 2021 Mar 3. doi:https://doi.org/10.3390/ijerph18052470

27. Boldt K, Coenen M, Movsisyan A, Voss S, Rehfuess E, Kunzler AM, Lieb K, Jung-Sievers C (2021) Interventions to ameliorate the psychosocial effects of the COVID-19 pandemic on children-a systematic review. Int J Environ Res Public Health 18(5):2361. https://doi.org/10.3390/ijerph18052361

28. Brooks SK, Webster RK, Smith LE, Woodland L, Wessely S, Greenberg N, Rubin GJ (2020) The psychological impact of quarantine and how to reduce it: rapid review of the evidence. Lancet 395(10227):912-920. https://doi.org/10.1016/S0140-6736(20) 30460-8

29. Marques de Miranda D, da Silva Athanasio B, Sena Oliveira AC, Simoes-E-Silva AC. How is COVID-19 pandemic impacting mental health of children and adolescents?. Int J Disaster Risk Reduct. 2020;51:101845. doi:https://doi.org/10.1016/j.ijdrr.2020.101845

30. Fegert JM, Vitiello B, Plener PL, Clemens V (2020) Challenges and burden of the Coronavirus 2019 (COVID-19) pandemic for child and adolescent mental health: a narrative review to highlight clinical and research needs in the acute phase and the long return to normality. Child Adolesc Psychiatry Ment Health 12(14):20. https://doi.org/10.1186/s13034-020-00329-3

31. Fegert JM, Kehoe LA, Çuhadaroglu Çetin F, Doyle M, Eliez S, Hebebrand J, Hillegers M, Karwautz A, Kotsis K, Kiss E, Pevjovic-Milovencevic M, Räberg Christensen AM, Raynaud JP, Anagnostopoulos D (2021) Next generation Europe: a recovery plan for children, adolescents and their families: for the time after the pandemic, we need a vision and investments for the future. Eur Child Adolesc Psychiatry 10:1-5. https://doi.org/10.1007/ s00787-021-01767-w 